\title{
Astronomical Algorithms: Amended Multi-millennia Calendar
}

\author{
Boris S. Verkhovsky \\ Computer Science Department, New Jersey Institute of Technology, \\ University Heights, Newark, USA \\ E-mail:verb73@gmail.com,verb@njit.edu \\ Received May 21, 2011; revised June 16, 2011; accepted June 20, 2011
}

\begin{abstract}
Three new worldwide calendars are proposed and compared in this paper. None of them requires any departure from an existing tradition to divide years on lean and leap. Although all three are pretty accurate, it is demonstrated that the Julian calendar with one additional amendment is the simplest and the most suitable for implementation.
\end{abstract}

Keywords: Astronomic Algorithm, Julian Calendar, Gregorian Calendar, Error Accumulation, Amendments, Multi-millennia Calendar, Synchronization

\section{Introduction and Gregorian Calendar}

Modern computing and communication systems require immensely high degree of synchronization, which in its turn requires measurement of time with great precision. Nowadays, atomic clock can measure time with accuracy smaller than one billionth of a second. Without such a precision numerous navigation systems including the GPS and other equivalents will not be able to properly operate.

Yet, modern calendars are highly inaccurate. Humankind has used and is currently using many calendars: Egyptian Calendar was introduced in the V Millennium BCE; the first year of Jewish calendar is 3760 BCE; Mayan chronology started from 3372 BCE. Six hundred years later (in 2772 BCE) Egypt adopted a calendar of 365 days without adjustments. Babylonian and Chinese astronomers learned about planetary movements in VIII century BCE. Julian calendar with leap years was adopted in 46 BCE, although the idea has been proposed 193 years earlier by Aristarchus from Alexandria. The average length of a year in the Julian calendar is 365.25 days. This is significantly different from the "real" length of the solar year. An error accumulates so fast that after about 131 years the calendar is out of sync by one day. By the 16th Century this affected the determination of the date of Easter.

Gregorian calendar was introduced in 1582 initially in France and the Netherlands, and 170 year later in Eng- land by an Act of Parliament. French Republican calendar was adopted in 1790s. Although Gregorian calendar was adopted in 1923 in the USSR, the Russian Orthodox Church does not recognize it and still celebrates Christmas thirteen days later. More details about various calendars are provided in [1-4]. Great mathematician and astronomer Carl F. Gauss proposed an algorithm that calculates Easter Sundays in the Gregorian calendar [5].

The Gregorian calendar is proposed by astronomers $\mathrm{C}$. Clavius and L. Lilio. It is basically a Julian calendar with two amendments, \{historic details are provided below\}.

It is reasonable to assume that when the Gregorian calendar has been introduced in XVI century, one of considerations was that such amendments would be easy to implement. Indeed, even with the generally low level of education at that time, there was no difficulty to recognize what year was divisible by 100 and what was divisible by 400 . With this pattern, a modified Julian calendar requires not two, but either three additional amendments \{as demonstrated in (10)-(14)\} or five additional amendments \{as demonstrated in (17)-(19)\}.

The existing Western calendar basically fluctuates between lean and leap years. A year is leap if it is divisible by four. However, a year ending with 00 is leap only if it is divisible by 400 . For instance, 1900 was lean year, but 1600 and 2000 were leap years.

Let $y$ be the $y$-th year of New Era. In order to find how many days $N(y)$ are in the $y$-th year, we use formula specified by Gregorian calendar: 


$$
N(y)=365+f(y, a)-f(y, b)+f(y, a b),
$$

where

$$
z=\{a, b\} ; a=4, \quad b=100 ;
$$

and let

$$
f(y, z):=\left\{\begin{array}{lll}
1, & \text { if } & y \bmod z=0 \\
0, & \text { if } & y \bmod z \neq 0
\end{array} .\right.
$$

Therefore, Equations (1)-(3) specify that leap years must be added every four years with an exception of those years that are divisible by 100 , but not divisible by 400. Assuming that $P_{1}=365$ and $P_{2}=365.25$, Formula (1) takes into account that the astronomic year, i.e., the period of rotation of the Earth around Sun is $P_{3}=365.242$ days [6].

For further verification, we also calculate the number of days $G(y)$ at the end of the $y$-th year from the beginning of the New Era.

Then

$$
G(y)=365 y+\lfloor y / 4\rfloor-\lfloor y / 100\rfloor+\lfloor y / 400\rfloor .
$$

For instance, at the end of the $100^{\text {th }}$ year $G(100)=36,500+25-1=36,524$; at the end of the $400^{\text {th }}$ year $G(400)=36,500 \times 400+100-4+1=144,097$; and at the end of the First Millennium

$G(1000)=365,000+250-10+2=365,242$. Yet, as it is demonstrated below, Gregorian calendar is correct for a relatively small number of centuries.

\section{Average Astronomical Year}

An average astronomical year is defined as a period with which the Earth rotates around Sun. The time from one fixed point, such as an equinox, to the next is called a tropical year. Its current length is 365.242190 days, but it fluctuates. In 1900 the period was 365.242196 days, and in 2100 it will be 365.242184 days. Thus, to get more accurate results, we must consider that in average

$$
P=365.24219, \quad[7,8] .
$$

\section{Inaccuracy in Gregorian Calendar}

\section{The first five millennia: Let}

$$
D(y):=y P
$$

Therefore, using $P$, we derive by direct computation that for $y=5000$

$$
D(5000)=1,826,211 .
$$

Yet, by Formula (4) for Gregorian calendar

$$
\begin{aligned}
& G(5000)=365 \times 5000+1250-50+12=1,826,212 . \\
& \text { Thus, } G(5000)-D(5000)=\mathbf{1} .
\end{aligned}
$$

Hence, as can be seen in (8), even the more accurate period of rotation $P=365.24219$ does not eliminate the discrepancy between the number of rotations around Sun and the corresponding number of days computed on the basis of Gregorian calendar.

The first ten millennia: For $y=10,000$

$$
D(10000)=3,652,422 \text {. }
$$

Yet, from (4)

$$
G(10000)=3,650,000+2500-100+25=3,652,425 \text {. }
$$

Hence, a three-day discrepancy will accumulate by the year $y=10,000$ if the Gregorian calendar is used.

\section{Astronomic Algorithm with the Fourth Amendment}

In the past, three amendments were introduced into the World calendar:

1) The Egyptians introduced 365 days instead of 360 days (the $1^{\text {st }}$ Amendment);

2) 365.25 days were introduced by Julian calendar (the $2^{\text {nd }}$ Amendment);

3) Further corrections were introduced by Gregorian calendar (the $3^{\text {rd }}$ Amendment), \{see (1)-(3)\}.

However, even these amendments do not provide an accurate account for a large period of time measured in millennia. To make the counting of the days more accurate, an additional (fourth) term should be introduced.

Step1.1: if 3200 divides $y$ then $y$-th year is lean; stop;

Step2.1: if 400 divides $y$ then $y$-th year is leap; stop;

Step3.1: if 100 divides $y$ then $y$-th year is lean; stop;

Step4.1: if 4 divides $y$ then $y$-th year is leap; stop; else $y$-th year is lean; stop.

The 4-th amendment provides a more accurate counting of the days for dozens of millennia ahead. From the fourth amendment in the astronomic algorithm (10) it follows that the 3200-th year, 6400-th year, 9600-th year etc. must be the lean years. As a result,

$$
V(y)=365 y+\lfloor y / 4\rfloor-\lfloor y / 100\rfloor+\lfloor y / 400\rfloor-\lfloor y / 3200\rfloor
$$

Finally, let $z=\{4,100,400,3200\}$; and let

$$
f(y, z):=\left\{\begin{array}{lll}
1, & \text { if } & y \bmod z=0 \\
0, & \text { if } & y \bmod z \neq 0 .
\end{array}\right.
$$

Then

$$
M(y)=365+f(y, 4)-f(y, 100)+f(y, 400)-f(y, 3200)
$$


However, there is a simpler solution with only one amendment to Julian calendar.

\section{Julian Calendar with One Amendment}

Step1.2: if 128 divides $y$ then $y$-th year is lean; stop;

Step2.2: if 4 divides $y$ then $y$-th year is leap else $y$-th year is lean; stop.

Mnemonic rule: After thirty one leap years skip one.

\section{Discrepancy Analysis}

Let $B(y)=365 y+\lfloor y / 4\rfloor-\lfloor y / 128\rfloor$;

then $B(y)$ is the number of days at the end of $y$-th year from the beginning of the New Era if the amended Julian calendar is used.

Let's compute $D(y)$ for $y=2,000 ; 3,200 ; 10,000$; 50,000 ; and 100,000; and compare them with corresponding values for $B(y), G(y)$ and $V(y)$ ssee Table 1\}:

From Table 2, it follows that Julian calendar with one additional amendment, or the Gregorian calendar with an additional amendment, provides the same accuracy. Thus, from our point of view, the former one should be implemented as the simplest.

Besides, it will be easy to introduce the Amended Julian calendar, because the first correction is required in 2048. Hence, the world community has sufficient time to incorporate this simple and beautiful calendar. Obviously, it is up to the international community to decide how the new calendar will be called. Excerpts of this paper were published in [9].

Table 1. Total number of days at the end of $y$-th year.

\begin{tabular}{lrrrrr}
\hline Errors & $\boldsymbol{y}=\mathbf{2 0 0 0}$ & $\boldsymbol{y}=\mathbf{3 2 0 0}$ & $\boldsymbol{y}=\mathbf{1 0 , 0 0 0}$ & $\boldsymbol{y}=\mathbf{5 0 , 0 0 0}$ & $\boldsymbol{y}=\mathbf{1 0 0 , 0 0 0}$ \\
\hline$D(y)$ & $730,484.38$ & $1,168,775.008$ & 3652421.9 & $18,262,109.5$ & $36,524,219$ \\
$B(y)$ & 730,485 & $1,168,775$ & $3,652,422$ & $18,262,110$ & $36,524,219$ \\
$G(y)$ & 730,485 & $1,168,776$ & $3,652,425$ & $18,262,125$ & $36,524,250$ \\
$V(y)$ & 730,485 & $1,168,776$ & $3,652,422$ & $18,262,110$ & $36,524,219$ \\
\hline
\end{tabular}

Table 2. Accumulated errors in days.

\begin{tabular}{cccccc}
\hline Errors & $\boldsymbol{y}=\mathbf{2 0 0 0}$ & $\boldsymbol{y}=\mathbf{3 2 0 0}$ & $\boldsymbol{y}=\mathbf{1 0 , 0 0 0}$ & $\boldsymbol{y}=\mathbf{5 0 , 0 0 0}$ & $\boldsymbol{y}=\mathbf{1 0 0 , 0 0 0}$ \\
\hline$|B(y)-D(y)|$ & 0.62 & 0.008 & 0.1 & 0.5 & 0 \\
$|G(y)-D(y)|$ & 0.62 & $\mathbf{0 . 9 9 2}$ & $\mathbf{3 . 1}$ & $\mathbf{1 5 . 5}$ & $\mathbf{3 1 . 0}$ \\
$|V(y)-D(y)|$ & 0.62 & 0.992 & 0.1 & 0.5 & 0 \\
\hline
\end{tabular}

\section{Alternative Algorithm for Calendar}

Step1.3: If 100,000 divides $y$ then $y$-th year is lean; stop;

Step2.3: if 5000 divides $y+a$ then $y$-th year is lean; stop;

Step3.3: if 2000 divides $y$ then $y$-th year is lean; stop;

Step4.3: if 400 divides $y$ then $y$-th year is leap; stop;

Step5.3: if 100 divides $y$ then $y$-th year is lean; stop;

Step6.3: if 4 divides $y$ then $y$-th year is leap else $y$-th year is lean; stop.

In this case

$A(y)=G(y)-\lfloor y / 2000\rfloor+\lfloor(y+a) / 5000\rfloor-\lfloor y / 100000\rfloor$,

where $a$ is an even positive integer such that $a \bmod 4 \neq 0$ or $a=100$.

Then

$$
\begin{aligned}
S(y)= & N(y)-f(y, 2000) \\
& +f(y+a, 5000)-f(y, 100000) .
\end{aligned}
$$

\section{Historic Details}

The Julian reform: Originally the Romans numbered years $\boldsymbol{a} \boldsymbol{b}$ urbe condita, that is, "from the founding of the city" (of Rome). After his conquest of Egypt in 48 B. C. Julius Caesar realized that the a.u.c. calendar was totally inappropriate to the needs of the new empire.

Peculiarities in modern calendar: Originally the Julian calendar was simple: all odd months had odd number of days (31 days each), and all even months, except February, had even number of days (30 days each). February had 29 days in lean years and 30 days in leap years. The seventh month was named in honor of Julius Caesar. Later the first Roman Emperor Caesar Augustus renamed the eighth month as Augustus and the number of days in August, previously 30 , now became 31 (the same as the number of days in July), "so that Augustus Caesar would not be regarded as inferior to Julius Caesar".

Consequently in the remaining months (SeptemberDecember) the numbers of days were swapped from 31 to 30 and vice verse. The extra day needed for August was taken from the end of February.

Remark: Maybe it will never become known why Caesar Augustus did not decide to rename the fifth or ninth month, which had thirty one days. Amazingly, this historic nonsense perpetuates more than two millennia. 
Table 3. Number of days in months.

\begin{tabular}{cccccc}
\hline Jan & Feb & Mar & Apr & May & Jun \\
31 & 30 & $31 / 30$ & 30 & 31 & 30 \\
\hline Jul & Aug & Sep & Oct & Nov & Dec \\
31 & 30 & 31 & 30 & 31 & 30 \\
\hline
\end{tabular}

The Gregorian reform: Pope Paul III recruited several astronomers to come up with a solution; one of them was Christopher Clavius (1537-1612). Various calendar reforms were proposed. When Pope Gregory XIII has been elected, he decided in favor of Clavius' reform [10,11].

\section{Alternate System of Counting Days in Months}

The self-explanatory Table $\mathbf{3}$ provides an alternate system of counting days in every month of each leap year; where March has thirty days in lean years.

\section{Acknowledgements}

I express my appreciation to J. W. Jones and J. Scher for comments, to W. Ambers for assistance in numerous computer experiments, to anonymous reviewers and the typesetter for their suggestions that improved this paper.

\section{References}

[1] L. E. Doggett, “Calendars,” In: P. K. Seidelmann, Ed., Explanatory Supplement to the Astronomical Almanac, US Naval Observatory, University Science Books Company, Mill Valley, 1992.

[2] D. D. McCarthy and P. K. Seidelmann, “TIME from
Earth Rotation to Atomic Physics,” Chapter 10 \& 11, Wiley-VCH, Weinheim, 2009. doi:10.1002/9783527627943

[3] J. H. Meeus, “Astronomical Algorithms," 2nd Edition, Willmann-Bell, Inc., Richmond, December 1999.

[4] B. Crun, "The Timetables of History: A Horizontal Linkage of People and Events,” Simon and Schuster, New York, 1979.

[5] C. F. Gauss, "Berechnung des Osterfestes," Monatliche Correspondenz zur Beförderung der Erd- und HimmelsKunde, Vol. 2, August 1800, pp. 121-130.

[6] K. Diem and C. Lentner, "Scientific Tables: Documenta Geigy,” 8th Edition, Ciba-Geigy, Tarrytown, 1986, pp. 206-207.

[7] B. A. Archinal, "Terrestrial Coordinates and the Rotation of the Earth,” Chapter 4, In: P. K. Seidelmann, Ed., Explanatory Supplement to the Astronomical Almanac, US Naval Observatory, University Science Books Company, Mill Valley, 1992, p. 253.

[8] C. Y. Hohenkerk, B. D. Yallop, C. A. Smith and A. T. Sinclair, "Celestial Reference Systems," Chapter 4, In: P. K. Seidelmann, Ed., Explanatory Supplement to the Astronomical Almanac, US Naval Observatory, University Science Books Company, Mill Valley, 1992, p. 116.

[9] B. Verkhovsky, "Amended Julian Worldwide Calendar," Annals of European Academy of Sciences, ISSN 13791982, European Academy of Sciences, Brussels, 2003, pp. 330-334.

[10] C. Clavius, "Romani Calendarii a Gregorio XIII Restituti Explicatio,” Opera Mathematica, Vol. 5, 1603, p. 13.

[11] Gregory XIII, “Inter Gravissimas,” W. Spenser and R. T. Crowley, Translation, International Organization for Standardization, Geneva, 2002 (Original work published in 1582). 